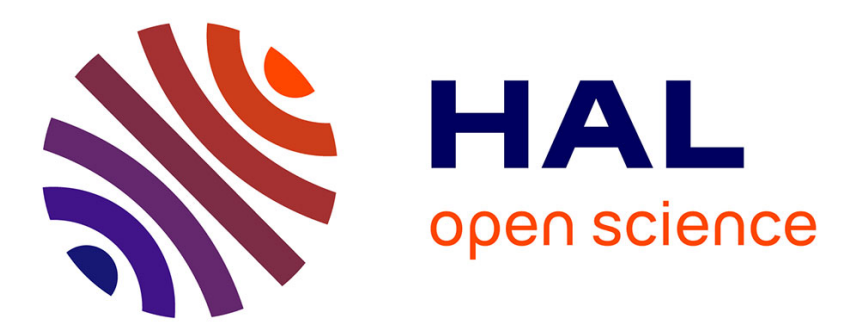

\title{
Adaptation of voluntary saccades, but not of reactive saccades, transfers to hand pointing movements
}

Julien Cotti, Alain Guillaume, Nadia Alahyane, Denis Pélisson, Jean-Louis

Vercher

\section{- To cite this version:}

Julien Cotti, Alain Guillaume, Nadia Alahyane, Denis Pélisson, Jean-Louis Vercher. Adaptation of voluntary saccades, but not of reactive saccades, transfers to hand pointing movements. Journal of Neurophysiology, 2007, 98 (2), pp.602-612. 10.1152/jn.00293.2007 . hal-01436037

\section{HAL Id: hal-01436037 https://hal.science/hal-01436037}

Submitted on 4 May 2018

HAL is a multi-disciplinary open access archive for the deposit and dissemination of scientific research documents, whether they are published or not. The documents may come from teaching and research institutions in France or abroad, or from public or private research centers.
L'archive ouverte pluridisciplinaire HAL, est destinée au dépôt et à la diffusion de documents scientifiques de niveau recherche, publiés ou non, émanant des établissements d'enseignement et de recherche français ou étrangers, des laboratoires publics ou privés. 
Julien Cotti, Alain Guillaume, Nadia Alahyane, Denis Pelisson and Jean-Louis

Vercher

J Neurophysiol 98:602-612, 2007. First published Jun 6, 2007; doi:10.1152/jn.00293.2007

You might find this additional information useful...

This article cites 74 articles, 23 of which you can access free at:

http://jn.physiology.org/cgi/content/full/98/2/602\#BIBL

Updated information and services including high-resolution figures, can be found at:

http://jn.physiology.org/cgi/content/full/98/2/602

Additional material and information about Journal of Neurophysiology can be found at: http://www.the-aps.org/publications/jn

This information is current as of January 24, 2008 . 


\title{
Adaptation of Voluntary Saccades, But Not of Reactive Saccades,
}

\section{Transfers to Hand Pointing Movements}

\author{
Julien Cotti, ${ }^{1}$ Alain Guillaume, ${ }^{1}$ Nadia Alahyane, ${ }^{2}$ Denis Pelisson, ${ }^{2}$ and Jean-Louis Vercher ${ }^{1}$ \\ ${ }^{1}$ Faculté des Sciences du Sport, Université de la Méditerranée, Centre National de la Recherche Scientifique, Unité Mixte de Recherche \\ 6152, Marseille; and ${ }^{2}$ Institut Federatif des Neurosciences de Lyon, Université Lyon 1, Institut National de la Santé et de la Recherche \\ Médicale, U534, Bron, France
}

Submitted 15 March 2007; accepted in final form 1 June 2007

Cotti J, Guillaume A, Alahyane N, Pelisson D, Vercher J-L. Adaptation of voluntary saccades, but not of reactive saccades, transfers to hand pointing movements. J Neurophysiol 98: 602-612, 2007. First published June 6, 2007; doi:10.1152/jn.00293.2007. Studying the transfer of visuomotor adaptation from a given effector (e.g., the eye) to another (e.g., the hand) allows us to question whether sensorimotor processes influenced by adaptation are common to both effector control systems and thus to address the level where adaptation takes place. Previous studies have shown only very weak transfer of the amplitude adaptation of reactive saccades-i.e., produced automatically in response to the sudden appearance of visual targets-to hand pointing movements. Here we compared the amplitude of hand pointing movements recorded before and after adaptation of either reactive or voluntary saccades, produced either in a saccade sequence task or in a single saccade task. No transfer to hand pointing movements was found after adaptation of reactive saccades. In contrast, a substantial transfer to the hand was obtained following adaptation of voluntary saccades produced in sequence. Large amounts of transfer between the two saccade types were also found. These results demonstrate that the visuomotor processes influenced by saccadic adaptation depend on the type of saccades and that, in the case of voluntary saccades, they are shared by hand pointing movements. Implications for the neurophysiological substrates of the adaptation of reactive and voluntary saccades are discussed.

IN T R O D U C T I O N

Visuomotor adaptation mechanisms continuously maintain the accuracy of visually guided movements. A fundamental issue in trying to understand the neural implementation of these adaptive mechanisms is whether they generalize across different body effectors. If the adaptation achieved for an effector affects movements made by another effector, then it can be concluded that this adaptation has influenced processes common to both effector control systems (Abeele and Bock 2003; Imamizu and Shimojo 1995; Morton and Bastian 2004; Seidler et al. 2001; Van Donkelaar et al. 1996).

Saccadic adaptation-i.e., the mechanisms that update the amplitude of saccades - have been quite extensively investigated (Hopp and Fuchs 2004). Nevertheless, the question of its transfer to hand pointing movements (HPM) is still debated. Indeed Bekkering et al. (1995) reported large transfer of saccadic adaptation to HPM, whereas Kroller et al. (1999) reported only very weak transfer. Methodological differences between these studies may explain these discrepancies. First, as

Address for reprint requests and other correspondence: A. Guillaume, CNRS/Université de la Méditerranée, UMR 6152 "Mouvement et Perception," Faculté des Sciences du Sport, 163 avenue de Luminy, 13288 Marseille Cedex 09, France (E-mail alain.guillaume@univmed.fr). underlined by Kroller et al. in Bekkering et al.'s experiment HPM were produced with concomitant saccades, which precluded evaluation of pure transfer of adaptation. Indeed, HPM could have been influenced by eye-hand coupling and not by plastic changes shared by the hand movements control system-i.e., the subjects could have pointed to where they were gazing (Feys et al. 2005; Van Donkelaar et al. 2002). Second, saccades were performed either with the head restrained (Bekkering et al. 1995) or with the head unrestrained (Kroller et al. 1999). Finally, Kroller et al.'s subjects were required to produce saccades in reaction to the sudden appearance of a peripheral target, whereas Bekkering et al.'s subjects were required to produce saccades between a fixation point and a target that were presented simultaneously from trial onset. In the latter study, the instruction to go (the extinction of the fixation point) was furthermore delivered without time uncertainty (i.e., 2,000 ms after the successful fixation). These latter differences in experimental paradigms could well have elicited different types of saccades: i.e., reactive saccades (RS) in Kroller et al.'s paradigm and voluntary saccades (VS) in Bekkering et al.'s paradigm.

Saccades are called reactive when elicited in reaction to the sudden appearance of a salient visual element. In contrast, saccades are called voluntary when triggered internally to redirect gaze between permanently visible objects. Psychophysical (e.g., Walker and McSorley 2006) and neurophysiological studies (e.g., Gaymard et al. 2003) have revealed significant differences between RS and VS. Converging evidences of a partial transfer of adaptation between the two saccade types also argue in favor of partial independence of adaptive processes between RS and VS (Alahyane et al. 2007; Collins and Doré-Mazars 2006; Deubel 1995; Erkelens and Hulleman 1993; Fujita et al. 2002; Gaveau et al. 2005).

In the present study, we investigated whether the type of saccade, RS or VS, determined the transfer of saccadic adaptation to another visually guided behavior: the HPM. The basic protocol consisted in evaluating changes in HPM amplitude consecutive to an adaptive amplitude reduction of either RS or VS. The head was restrained in all conditions. Importantly, the potentially confounding factor present in the study of Bekkering et al. (1995) has been avoided-i.e., HPM were tested without concomitant saccades. We tested the transfer to HPM after adaptation of the two types of saccades in classical paradigms: RS toward a suddenly appearing single target

The costs of publication of this article were defrayed in part by the payment of page charges. The article must therefore be hereby marked "advertisement" in accordance with 18 U.S.C. Section 1734 solely to indicate this fact. 
(single saccade task) and sequence of scanning VS between simultaneously displayed targets (saccade sequence task). We also designed mixed conditions to assess the role of the complexity of the task: RS in saccade sequence task and VS in single saccade task. Transfers of adaptation across saccade types were additionally reinvestigated.

Preliminary data of this study were published previously in abstract form (Cotti et al. 2006).

\section{METHODS}

\section{Subjects}

Sixty subjects volunteered to take part in the experiment. All were self-declared right-handed, 20-31 yr of age (mean $=25$ ), and healthy, with normal or corrected-to-normal vision. They were naïve as to the purpose of the experiment. Before the experiment, the subjects gave their informed consent to participate to the study, which was performed in accordance with the ethical standards established in the 1964 Declaration of Helsinki. Subjects were randomly assigned to one of six groups of ten subjects. The experimental design constituted six experimental sessions that each involved one of these groups (Table 1).

\section{Apparatus}

Subjects were seated in complete darkness on an ergonomic posture chair, the head maintained straight ahead by a chin rest and a frontal support (Fig. 1). Visual stimuli were projected (LCD projector) onto a horizontal semiopaque screen (plane $a$ ) by the use of a mirror. Subjects faced a second oblique mirror (plane $b$ ), which reflected the images created on the semiopaque screen. This setup created the illusion that visual targets were presented at the level of a third plane (c) that corresponded to the surface of a large digitizing tablet (SummaGrid IV, 0.1-mm accuracy, $100 \mathrm{~Hz}, 60 \times 90 \mathrm{~cm}$ ). The distance between plane $c$ and the subjects' eyes was $57 \mathrm{~cm}$. Consequently, $1 \mathrm{~cm}$ on this plane corresponded to $1^{\circ}$ of ocular deviation, allowing direct comparison between amplitude changes of saccades (in degrees) and HPM (in centimeters). Subjects were required to execute either leftward HPM with a stylus on the digitizing tablet or leftward saccades toward two possible targets that appeared at 20 or $30^{\circ}$ from a fixation point (FP), these targets defining two required vectors (movements to be produced by the subject). The FP was located $20^{\circ}$ to the right of the sagittal plane. The targets and the FP were presented on a black background and consisted of red circles (subtending $0.5^{\circ}$ of visual angle) with a black center to favor foveation. Because HPMs were executed underneath the mirror, there was no visual feedback of hand movements. A helmet-mounted infrared sensor allowed the recording of left eye position at $250 \mathrm{~Hz}$ (EyeLink video-oculographic system, SMI, Berlin, Germany) with a spatial resolution of $<0.1^{\circ}$. The calibration was performed with EyeLink software using a nine-point calibration grid that allowed precise measurements of horizontal and vertical eye position. A real-time acquisition system (Keithley Instruments, Cleveland, $\mathrm{OH}$ ) controlled the experiments using laboratory-made software (Docometre). In particular, real-time monitoring of eye position allowed us to modify the visual display during saccades within $12 \mathrm{~ms}$ of a predefined event trigger, i.e., when the horizontal eye velocity exceeded a $30 \%$ threshold.

\section{Experimental procedures}

Each experimental session was composed of several phases detailed in Table 1. Comparisons between movement parameters for RS, VS, or HPM obtained before (PRE) and after (POST) the exposure phases allowed us to assess the effect of the adaptation. For the adapted saccadic type, an additional postexposure phase was conducted at the end of the experimental session (POST2) to evaluate any possible saccadic deadaptation during the different postexposure phases. The adaptation of RS or VS was induced during the exposure phase by stepping backward the single target or the target ensemble during each saccade corresponding to the required vector, detected by the automated velocity threshold (double-step paradigm). RSsing and RSseq were designed to induce RS adaptation in single saccade task and in saccade sequence task, respectively. VSsing and VSseq were similarly designed to assess the effect of VS adaptation in single and sequence tasks. RScont and VScont were control sessions identical to RSsing and VSseq except for the pseudo "exposure" phase (i.e., no target's backward step occurred in this phase) and aimed at evaluating possible changes of amplitude of eye and hand movements not related to saccadic adaptation (e.g., arising from fatigue).

During pre- and postexposure phases, the trials had a constant duration of $3 \mathrm{~s}$, during which the subjects were always required to produce a single movement according to the following protocols. In RS-PRE (evaluation of the baseline amplitude of RS), RS-POST1, and RS-POST2 (evaluation of RS amplitude after exposure phase), subjects were required to execute a leftward saccade, as fast and as accurately as possible, triggered by the randomly timed appearance of one of the two peripheral targets $\left(20\right.$ or $30^{\circ}$ on the left of the FP).

TABLE 1. Experimental design: experimental phases of the six Experimental Sessions

\begin{tabular}{|c|c|c|c|c|c|c|c|c|}
\hline \multirow{2}{*}{$\begin{array}{l}\text { Experimental } \\
\text { Session } \\
\text { RSsing }\end{array}$} & \multicolumn{8}{|c|}{ Experimental Phase } \\
\hline & HPM-PRE & VS-PRE & RS-PRE & $\begin{array}{l}\text { RSsing-Exposure } \\
300 \text { trials } \times \text { single saccade task } \\
150 \text { backward steps per required vector }\end{array}$ & RS-POST1 & HPM-POST & VS-POST & RS-POST2 \\
\hline RSseq & HPM-PRE & VS-PRE & RS-PRE & $\begin{array}{l}\text { RSseq-Exposure } \\
200 \text { trials } \times \text { saccade sequence task } \\
200 \text { backward steps per required vector }\end{array}$ & RS-POST1 & HPM-POST & VS-POST & RS-POST2 \\
\hline VSsing & HPM-PRE & RS-PRE & VS-PRE & $\begin{array}{l}\text { VSsing-Exposure } \\
300 \text { trials } \times \text { single saccade task } \\
150 \text { backward steps per required vector }\end{array}$ & VS-POST1 & HPM-POST & RS-POST & VS-POST2 \\
\hline VSseq & HPM-PRE & RS-PRE & VS-PRE & $\begin{array}{l}\text { VSseq-Exposure } \\
150 \text { trials } \times \text { saccade sequence task } \\
150 \text { backward steps per required vector }\end{array}$ & VS-POST1 & HPM-POST & RS-POST & VS-POST2 \\
\hline RScont & HPM-PRE & & RS-PRE & $\begin{array}{l}\text { RScont-Pseudo-Exposure } \\
150 \text { trials } \times \text { single saccade task }\end{array}$ & RS-POST1 & HPM-POST & & RS-POST2 \\
\hline VScont & HPM-PRE & & VS-PRE & $\begin{array}{l}\text { VScont-Pseudo-Exposure } \\
150 \text { trials } \times \text { saccade sequence task }\end{array}$ & VS-POST1 & HPM-POST & & VS-POST2 \\
\hline
\end{tabular}

For the labels of Experimental Sessions, "sing" and "seq" refer to "single saccade task" and "saccade sequence task", respectively. For Experimental Phases, "PRE" and "POST" refer to the tests of amplitude performed before and after the exposure phases. See Experimental procedures in METHODS for further details. 

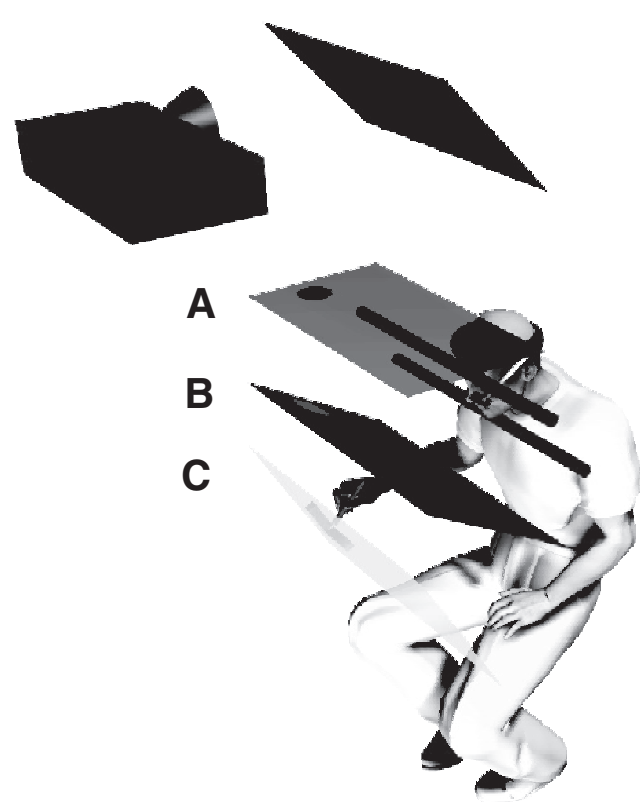

FIG. 1. Visual stimuli were projected onto a horizontal semiopaque screen (plane $a$ ) by the use of a mirror. Subjects faced a second oblique mirror (plane $b$ ) that reflected the images created on the semiopaque screen (plane $a$ ). This setup created the illusion that visual targets were at the level of a third plane (c) that corresponded to the surface of a large digitizing tablet.

Extinction of the FP was synchronized with the target onset. To avoid any feedback on saccade accuracy, the target was extinguished when the eye-velocity threshold was reached. In VS-PRE (evaluation of the baseline amplitude of VS), VS-POST1, and VS-POST2 (evaluation of VS amplitude after exposure phase), subjects were required to execute a self-paced and internally triggered saccade starting from FP and directed toward a target presented at 20 or $30^{\circ}$ on the left. FP and one of these two possible targets were both lit at trial onset and were extinguished during the leftward saccade (detected by use of the velocity threshold). Subjects were additionally instructed before each VS experimental phase to voluntarily change the moment of the saccade triggering from one trial to the next, to reinforce the voluntary nature of the behavior. In HPM-PRE (evaluation of the baseline amplitude of HPM) and HPM-POST (evaluation of HPM amplitude after the exposure phase of RS or VS), each trial started with the handheld stylus positioned in an L-shaped piece of wood. This setup did not hamper the subsequent leftward movement and ensured that the starting position of the stylus corresponded precisely to the visual FP. At the randomly timed appearance of one of the two targets, subjects were asked to point with the stylus toward this target while keeping their gaze on the FP throughout the trial. If an eye displacement was detected (velocity threshold) the FP and the target disappeared and the trial was cancelled. Each PRE and POST exposure phase constituted 20 trials for each of the two required vectors, randomly distributed in the phase.

The adaptation of RS in a single saccade task (RSsing-Exposure) corresponded to a classical double-step paradigm (Fig. 2A). Instructions for subjects were the same as in RS-PRE and RS-POST. The trial design was also the same except on two points. First, during the leftward saccade produced in reaction to the first target's step the target shifted backward (to the right) by an amount representing $30 \%$ of the initial required vector (i.e., 6 and $9^{\circ}$, respectively, for 20 and $30^{\circ}$ required vectors). Second, the target in the new position remained lit until the end of the trial. As a result of the phenomenon of saccadic suppression (Bridgeman et al. 1975; Matin 1974), the target's backward step remained unperceived by subjects. Because of this backward step, the first saccade "missed" the target and an additional "corrective" saccade was produced to foveate the new target position.
Gradually, subjects unconsciously reduced the amplitude of the primary saccade, so that their gaze directly fell on the second target position at the end of the exposure phase. Typical horizontal eye displacements in the early and late parts of the exposure phase are shown in Fig. 2A. RSsing-Exposure constituted 300 trials (150 for each required vector, randomly distributed in the phase).

The adaptation of RS in a saccade sequence task (RSseq-Exposure) was obtained by the use of a paradigm inspired from Deubel (1995) and requiring the scanning of a scene with RS (Fig. 2B). In this case, the duration of one trial was $6 \mathrm{~s}$. Subjects were instructed to explore a scene, always following the same predetermined scan path. Trials were designed to elicit RS for the two required vectors. A scene of three targets distributed above and below the horizontal midline $\left(7^{\circ}\right.$ of vertical separation) was presented from the beginning of the trial. The two bottom targets could form either the 20 or $30^{\circ}$ required vector. At the beginning of the trial, the subject was required to look at the top right target. From this first FP, the subject had to react as quickly and precisely as possible to the random appearance of a top left target 1,000 to $1,400 \mathrm{~ms}$ after trial onset. During this first leftward horizontal saccade (detected by use of the velocity threshold) the whole scene was displaced rightward of $30 \%$ of the amplitude of the required vector. Simultaneously, the bottom left target was turned off. After a short fixation of self-determined duration on the top left target, the subject had to make an oblique saccade to look at the lower right target that became the second FP. A bottom left target reappeared at a randomized time 2,000 to 2,400 ms after onset of the first leftward saccade. The position of this lower left target was randomly chosen to form either a 20 or $30^{\circ}$ required vector (possibly different from the bottom required vector presented at the beginning of the trial). The subject had to produce a second RS that triggered a second rightward displacement of the whole scene of $30 \%$ of the required vector. The temporal and spatial uncertainty concerning the appearance of the left targets prevented any voluntary planning of the leftward saccades. Because pilot studies showed that adaptation of RS in the saccade sequence task was slower than that obtained in all other exposure phases, RSseq-Exposure consisted of 200 trials; and because each trial induced two saccades, 400 leftward saccades with intrasaccadic step were performed (counterbalanced to reach 200 for each required vector vs. 150 trials for all the other exposure phases).

The adaptation of VS in a single saccade task (VSsing-Exposure) was induced by the use of an adapted version of the classical double-step paradigm (RSsing-Exposure) that differed from the latter in that the FP and the left peripheral target were simultaneously presented to the subject (Fig. 2C). The subject was required to internally trigger a single leftward saccade, which simultaneously triggered the extinction of the FP and a rightward step of the peripheral target (30\% of the required vector). As previously described for VS-PRE and VS-POST phases, the subject was required to voluntarily vary the moment of the saccade triggering from one trial to the next one. VSsing-Exposure constituted 300 trials (150 for each required vector, randomly distributed in the phase).

The adaptation of VS in a saccade sequence task (VSseq-Exposure) was obtained by the use of a scanning scene paradigm very similar to that described for RSseq (Fig. 2D). In this case, the complete scene consisting of four targets was presented from the onset of the trial: the two required vectors $\left(20\right.$ and $30^{\circ}$ ) positioned randomly above and below the horizontal meridian of the screen. Subjects were instructed to perform a self-paced but predetermined saccadic scan path (identical to RSseq) to explore targets: look at the upper right target, look at the upper left target (first leftward horizontal saccade), make an oblique saccade to look at the lower right target, and finally look at the lower left target (second leftward horizontal target). During each leftward saccade (detected by the use of the velocity threshold) the whole scene was shifted rightward of $30 \%$ of the currently required vector. Additionally, the subject was required to voluntary vary the triggering of each produced VS (see VS-PRE, VS-POST, and VSsing- 
A RSsing-Exposure

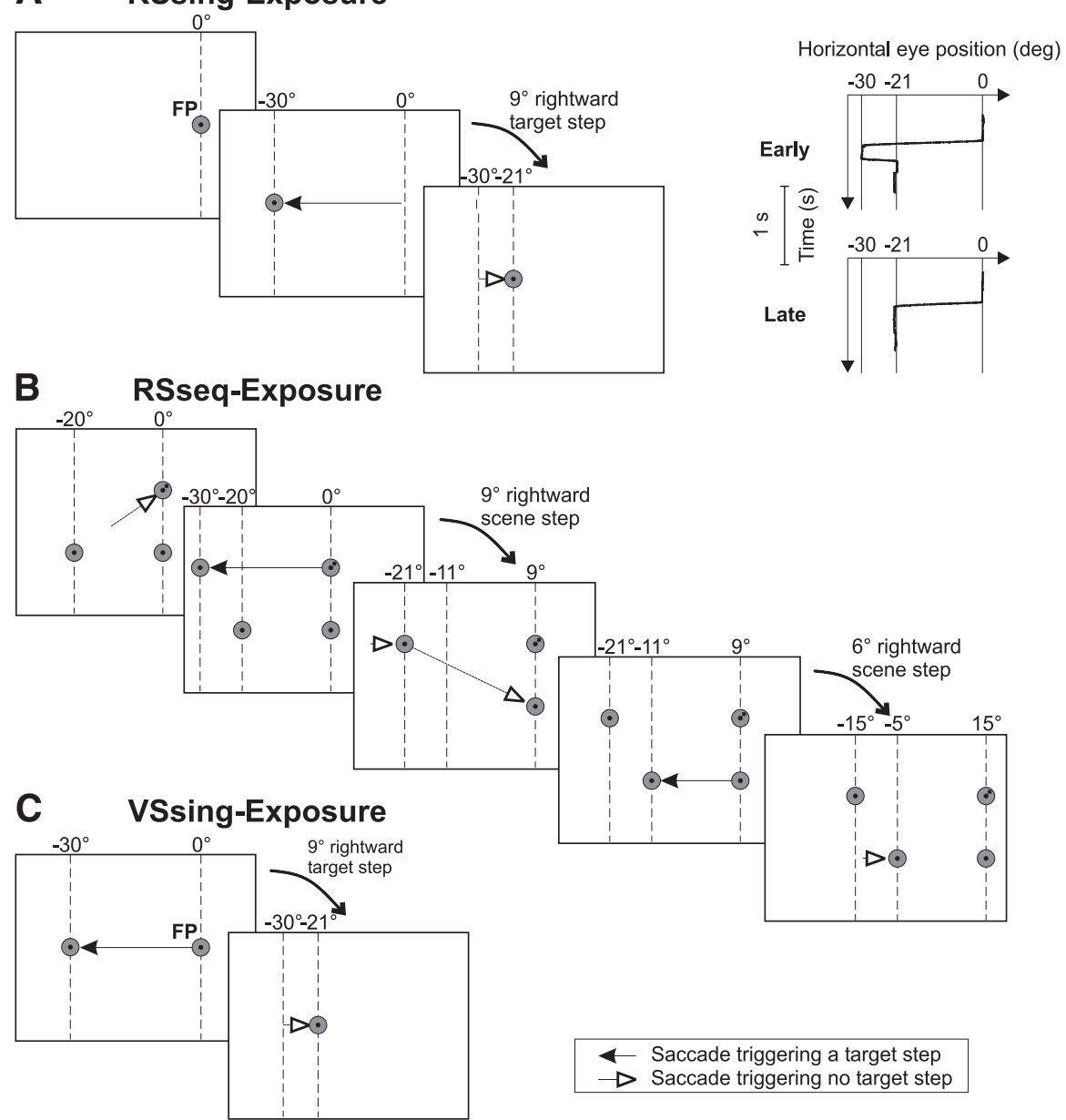

FIG. 2. Adaptive protocols. Black and white arrows correspond to saccades inducing a target step or not, respectively. A: adaptation of reactive saccade (RS) in a single saccade task ("sing") was induced by use of the classical double-step paradigm. $B$ : adaptation of RS in a saccade sequence task ("seq") was induced by use of a scanning scene paradigm. At the end of each trial subjects were additionally required to report the number of targets that were altered in the scene (targets with the red circle truncated by black pixels). $C$ : adaptation of voluntary saccade (VS) in a single saccade task was induced by use of a paradigm similar to that used in RSsing-Exposure, except that the fixation point (FP) and target were presented simultaneously from the onset of the trial. $D$ : adaptation of VS in saccade task was induced by use of a scanning scene paradigm similar to that used in RSseq-Exposure. Subjects were required to complete a discrimination task as in RSseq-Exposure. Rightmost subplots show representative horizontal eye displacement early and late in the RSsing- and VSseq-Exposure phases.

\section{VSseq-Exposure}

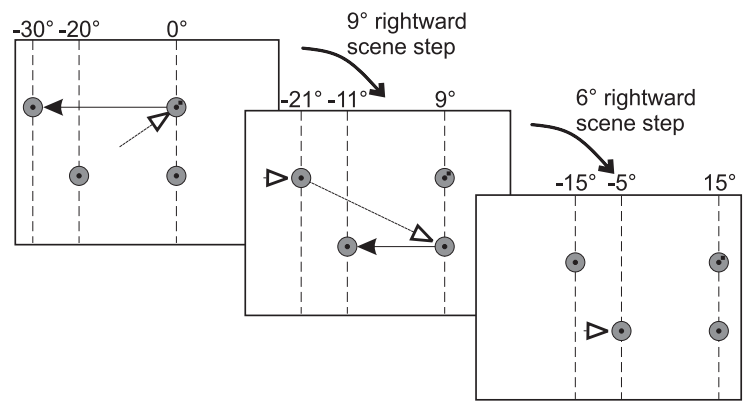

Exposure). Example traces show the disappearance or the reduction of corrective saccades in late trials (Fig. 2D). Because each trial contained the two required vectors, 300 leftward saccades with intrasaccadic step were performed (150 for each required vector).

Similar to Deubel's paradigm, subjects of VSseq performed a discrimination task to reinforce the self-paced, voluntary nature of their scanning saccades: a random number of targets (zero to four) presented alterations (the red circle of the target was truncated by black pixels) and subjects had to report this number at the end of each trial. Responses, given by means of button presses, were monitored on-line by experimenters to give feedback to subjects on their performance but were not recorded. Note that this discrimination task also forced precise foveation (each target alteration subtended $<0.1^{\circ}$ of visual angle). To balance a potential effect of this discrimination task on transfers of adaptation, subjects of RSseq were also required to

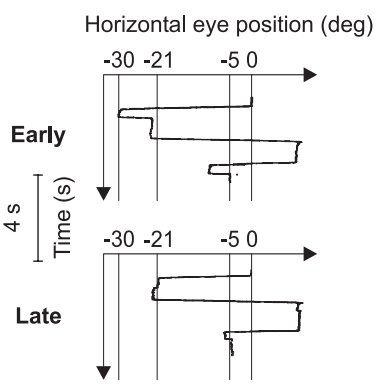

perform this discrimination task during the exposure phase (RSseqExposure).

In RScont and VScont (control sessions), pseudo-exposure phases were identical to exposure phases conducted for the corresponding RSsing and VSseq except that no intrasaccadic target step occurred.

\section{Analysis}

The amount of saccadic adaptation was defined as the ratio between the observed saccadic amplitude change, induced by the adaptive procedure, and the required amplitude change, following Eq. 1. To take into account any potential saccadic deadaptation during the several POST exposure phases, baseline saccadic amplitudes of the adapted saccade type evaluated before adaptation (PRE) were compared with the amplitudes measured after the adaptation, averaging 
values of the two postexposure phases (POST1 and POST2) carried out for the adapted saccade type. The 0.3 factor allows determination of the required amplitude change, which was calculated as $30 \%$ of the currently required vector (i.e., $6^{\circ}$ for the $20^{\circ}$ required vector and $9^{\circ}$ for the $30^{\circ}$ required vector)

Amount of adaptation

$$
=\frac{\begin{array}{l}
\text { (saccadic amplitude PRE }- \\
\text { mean saccadic amplitude across POST1 and POST2, } \times 100
\end{array}}{\text { required vector } \times 0.3}
$$

The amount of transfer of saccadic adaptation to HPM was computed following $E q$. 2. The difference between HPM amplitude before saccadic adaptation (PRE) and HPM amplitude after saccadic adaptation (POST) was compared with the saccadic amplitude change induced by the adaptive procedure

Amount of transfer to HPM

$$
=\frac{(\text { HPM amplitude PRE }- \text { HPM amplitude POST, } \times 100}{\text { saccadic amplitude PRE }}
$$

The amount of transfer of the adaptation of one type of saccades to the other type was defined as the ratio between the amplitude change of the nonadapted saccade type and the saccadic amplitude change induced for the adapted saccade type by the adaptive procedure (simply replacing in Eq. 2 the HPM amplitude change by the differ- ence between nonadapted saccade amplitude before and after the exposure phase of the adapted saccade type).

Statistical analysis was performed using Statistica for Windows, release 7.1 (StatSoft). Mean horizontal amplitudes of saccades and HPM were submitted to partially repeated measures ANOVAs with "Experimental Session" (RSsing, RSseq, VSsing, or VSseq) as categorical predictor and "Required Vector" $\left(20\right.$ or $\left.30^{\circ}\right)$ and "Experimental Phase" (PRE or POST) as within-subjects factors. Median latencies of saccades, amounts of saccadic adaptation for RS and VS, and amounts of transfer to the nonadapted saccade type were averaged on the two required vectors and submitted to ANOVAs with "Experimental Session" (RSsing, RSseq, VSsing, or VSseq) as categorical predictor. Significant differences were followed up with NewmanKeuls post hoc tests (statistical threshold of $P<0.05$ ).

\section{RE S U L T S}

Time-courses of representative sessions are presented in Fig. 3 for RSsing (Fig. 3A) and VSseq (Fig. 3B). Each symbol corresponds to a single movement. The $x$-axes represent the whole course of these experimental sessions. For the sake of clarity, symbols corresponding to the movements produced for the $20^{\circ}$ required vector are not shown. Because the occurrence of the two required vectors $\left(20\right.$ and $\left.30^{\circ}\right)$ was randomized and because each movement is plotted at its real rank of occurrence in the experimental session, the space between the remaining symbols $\left(30^{\circ}\right.$ required vector) is variable. The different phases
A

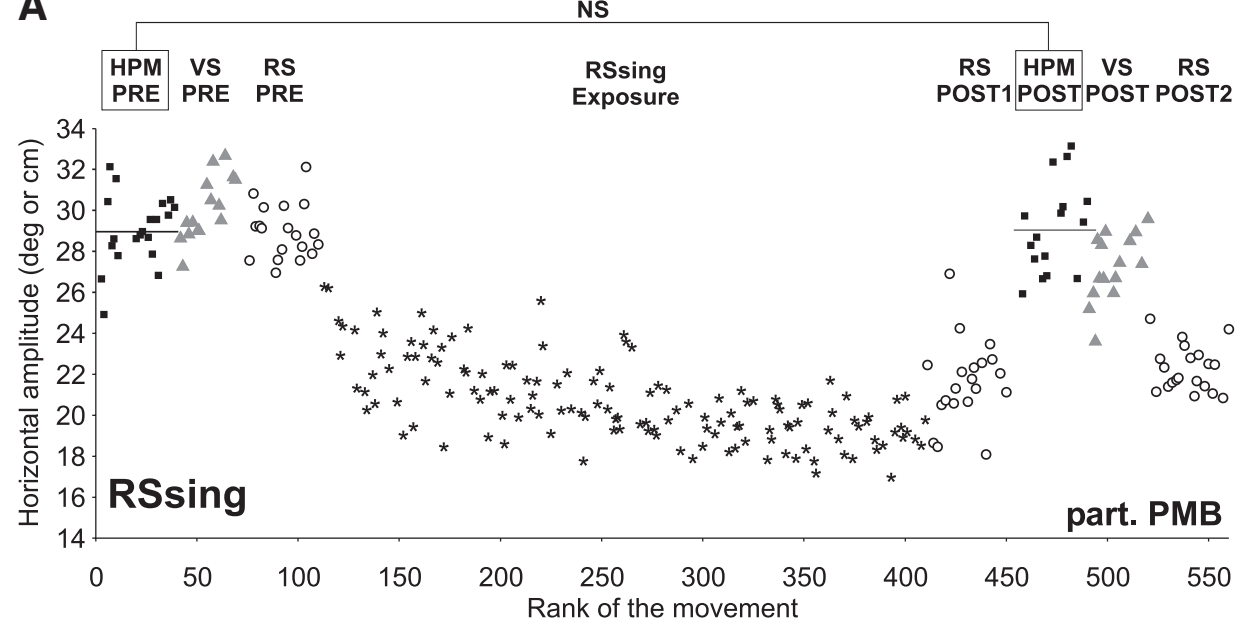

B

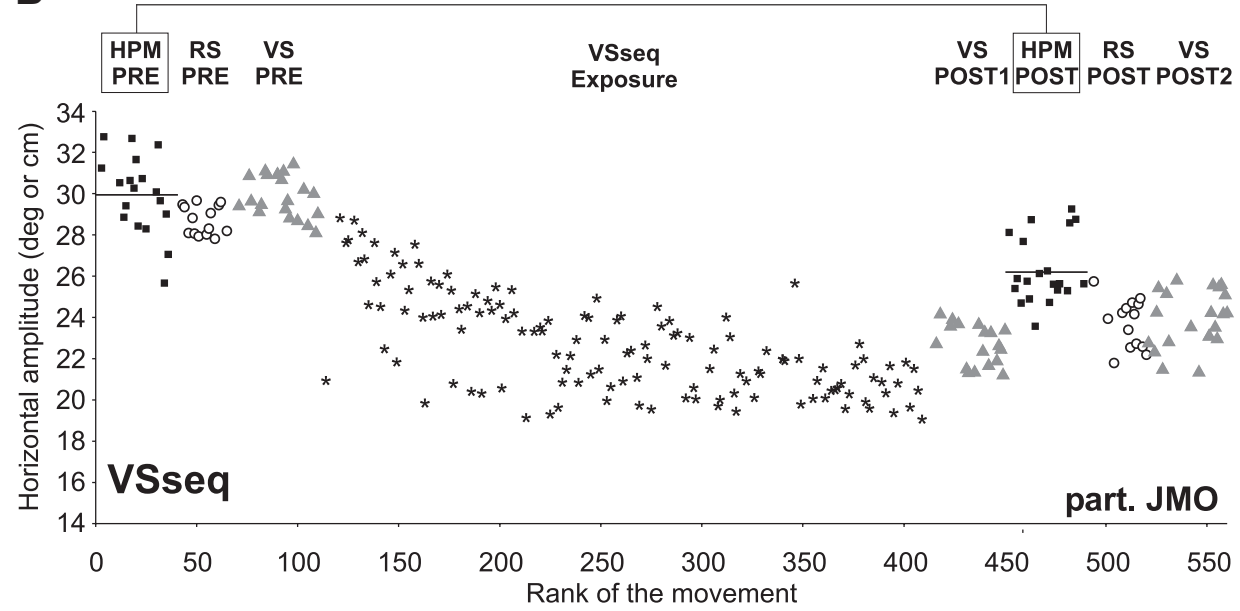

FIG. 3. Horizontal amplitude of saccades and hand pointing movements (HPM) of representative subjects of RSsing and VSseq. $x$ axes represent the whole experimental session but only $30^{\circ}$ required vector data are presented. Each amplitude is plotted as a function of the rank of the considered movement (saccade or HPM) in the experimental session. Because the randomly interleaved $20^{\circ}$ required vector data are not shown, horizontal spacing between symbols is not regular. Open circles, gray triangles, and black squares show RS, VS, and HPM horizontal amplitude, respectively. Black stars show horizontal amplitude of the adapted saccades during the exposure phase. Labels of the experimental phases are presented above each graph. Asterisks indicate differences that were statistically significant between preexposure ("PRE") and postexposure ("POST") HPM horizontal amplitude $(* * P<0.01$, Student's $t$-test). A: horizontal amplitude of HPM, $\mathrm{VS}$, and RS before and after RS adaptation induced by a single saccade task. $B$ : horizontal amplitude of HPM, RS, and VS before and after VS adaptation induced by a saccade sequence task. 
of these experimental sessions are indicated in the top part of the graphs (see also Table 1).

In the RSsing example (test of the transfer to HPM of RS adaptation in a single saccade task; Fig. 3A), the mean amplitude of RS before the adaptive phase was $29.1 \pm 1.3^{\circ}$ (mean \pm $\mathrm{SD})$. Intrasaccadic target steps during the adaptive phase led to a progressive amplitude decrease. After this adaptive phase, the mean amplitude of RS (averaged on RS-POST1 and RSPOST2) was $21.9 \pm 1.7^{\circ}$, giving a PRE - POST amplitude difference of $7.2^{\circ}$. Thus for this subject and for this $30^{\circ}$ required vector, the ratio between the actual and the required $\left(9^{\circ}\right)$ decrease of amplitude defined an amount of adaptation of $80 \%$. On the contrary, HPM amplitudes before (HPM-PRE) and after (HPM-POST) RS adaptation did not differ significantly $(29.0 \pm 1.7$ vs. $29.1 \pm 2.2 \mathrm{~cm} ; P>0.05$, Student's $t$-test). The ratio of this change of HPM amplitude $(0.1 \mathrm{~cm})$ on the change of RS amplitude $\left(7.2^{\circ}\right)$ defined a transfer of RS adaptation to HPM of $-1.4 \%$ for this subject. Note that this negative value indicating a lengthening of HPM amplitude is a result opposite to what was expected had a transfer of adaptation occurred. VS amplitude data recorded in RSsing will be considered at the end of the RESULTS section.

In the VSseq example (test of the transfer to HPM of VS adaptation in a saccade sequence task; Fig. 3B), the exposure phase with a saccade sequence task produced a progressive reduction of VS amplitude (reaching $6.5^{\circ}$ ). The mean saccadic amplitude in VS-PRE was $29.8 \pm 1^{\circ}$ and shortened to $23.3 \pm$ $1.4^{\circ}$ (average on VS-POST1 and VS-POST2). The amount of adaptation was thus $72.2 \%$. After this VS adaptation, HPM amplitude was significantly reduced (by $3.6 \mathrm{~cm}$ ): mean amplitudes for HPM-PRE and HPM-POST were $29.9 \pm 1.9$ and $26.3 \pm 1.6 \mathrm{~cm}$, respectively $(P<0.001$, Student's $t$-test). This revealed a $55.4 \%$ transfer of VS adaptation to HPM. RS amplitude data recorded in VSseq will be considered at the end of the RESULTS section. The time courses of the experimental sessions RSseq and VSsing are very similar and thus not illustrated.

All the following analyses were carried out on ten subjects for RSsing, VSsing, and VSseq but on nine subjects for RSseq because one subject did not present any adaptive effect after the exposure phase.

\section{Saccadic latencies}

Consistently with their distinct triggering mechanisms, reactive and voluntary saccades present distinct latency distributions. For RS, latency refers to the time between target onset and eye displacement onset, whereas for VS, latency refers to the duration of the fixation period preceding the saccade. Concerning PRE and POST phases (pooled together), saccadic latencies differ significantly across Experimental Session [ANOVA; $F(3,35)=31.44, P<0.001]$. Post hoc breakdown of this main effect showed that RS latencies did not differ significantly across RS experimental sessions and reached $236 \pm 35 \mathrm{~ms}$ in RSsing and $229 \pm 18 \mathrm{~ms}$ in RSseq (mean, across subjects, of each subject's median value $\pm \mathrm{SD} ; P>$ 0.05, Newman-Keuls post hoc tests). VS latencies were significantly higher than RS latencies and also differed between VS experimental sessions, reaching $897 \pm 298 \mathrm{~ms}$ in VSsing versus $571 \pm 180 \mathrm{~ms}$ in VSseq $(P<0.001$, ANOVA, Newman-Keuls post hoc tests). Saccadic latencies were analyzed separately for the exposure phases to ensure that the adaptive paradigms elicited saccades of different types (RS or VS) and these latencies differ again significantly across Experimental Session [ANOVA; $F(3,35)=42.70, P<0.001$ ]. Latencies during exposure phases reached $210 \pm 24 \mathrm{~ms}$ in RSsing, $270 \pm$ $27 \mathrm{~ms}$ in RSseq, $865 \pm 236 \mathrm{~ms}$ in VSsing, and $506 \pm 149 \mathrm{~ms}$ in VSseq. Post hoc breakdown of the Experimental Session effect showed that latencies for the two RS experimental sessions were not significantly different from each other but the VS latencies were always much longer and differed between VS experimental sessions. The very high variability observed in the two VS experimental sessions largely resulted from the instruction given to the subjects, i.e., they were told to vary the moment of their saccade triggering (see METHODS). These results suggest that our protocols successfully induced two different types of saccades: RS and VS.

\section{Amounts of saccades and HPM amplitude change}

A summary of mean changes of horizontal amplitude between preexposure and postexposure phases for saccades and HPM obtained in each experimental session is presented in Fig. 4 for 20 and $30^{\circ}$ required vectors. Concerning the saccadic amplitudes first, an ANOVA revealed a significant interaction between Experimental Session, Experimental Phase, and Required Vector $[F(5,53)=11.72, P<0.001]$. Post hoc breakdown of this interaction showed that the shortenings between pre- and postexposure phases of RS and VS observed in RSsing, RSseq, VSsing, and VSseq were significant (Fig. 4, $A-D ; P<0.001$, Newman-Keuls post hoc tests). Importantly, these shortenings were attributed to the adaptive protocol. Indeed, no significant saccadic amplitude change occurred in control experiments RScont and VScont (Fig. 4, $F$ and $G ; P>$ 0.05 , Newman-Keuls post hoc tests). Furthermore, the amplitude shortening was always larger for the $30^{\circ}$ than that for the $20^{\circ}$ required vector, which resulted from the experimental protocol defining a larger backward step of the target for the $30^{\circ}$ than for the $20^{\circ}$ required vector ( 9 and $6^{\circ}$, respectively).

An ANOVA on HPM amplitude revealed a significant interaction between Experimental Session, Experimental Phase, and Required Vector $[F(5,53)=2.72, P<0.05]$. Post hoc breakdown of this interaction showed that the significant amplitude shortenings occurred only after the adaptation of VS. Indeed, after the adaptation of sequence of VS, HPM amplitudes for the two required vectors were significantly reduced (VSseq, see Fig. 4D; $P<0.001$, Newman-Keuls post hoc tests). Concerning VSsing, a large and significant difference of HPM amplitude between PRE- and POST-exposure phases was observed, but only for the $30^{\circ}$ required vector (Fig. $4 B$; $P<0.05$, Newman-Keuls post hoc tests). On the contrary, neither RS adaptation in the single saccade task (RSsing) nor $\mathrm{RS}$ adaptation in the saccade sequence task (RSseq) induced HPM amplitude changes that reached significance (Fig. 4, A and $C$ ). Importantly, this analysis also confirmed that the observed shortenings of HPM amplitude were specifically associated with saccadic adaptation. Indeed, we observed no statistically significant shortening of HPM amplitudes in control sessions (RScont and VScont). The only significant change of HPM amplitude reported in these control sessions was a short lengthening for the $20^{\circ}$ required vector. These observations draw aside the hypothesis of a nonspecific effect (e.g., 

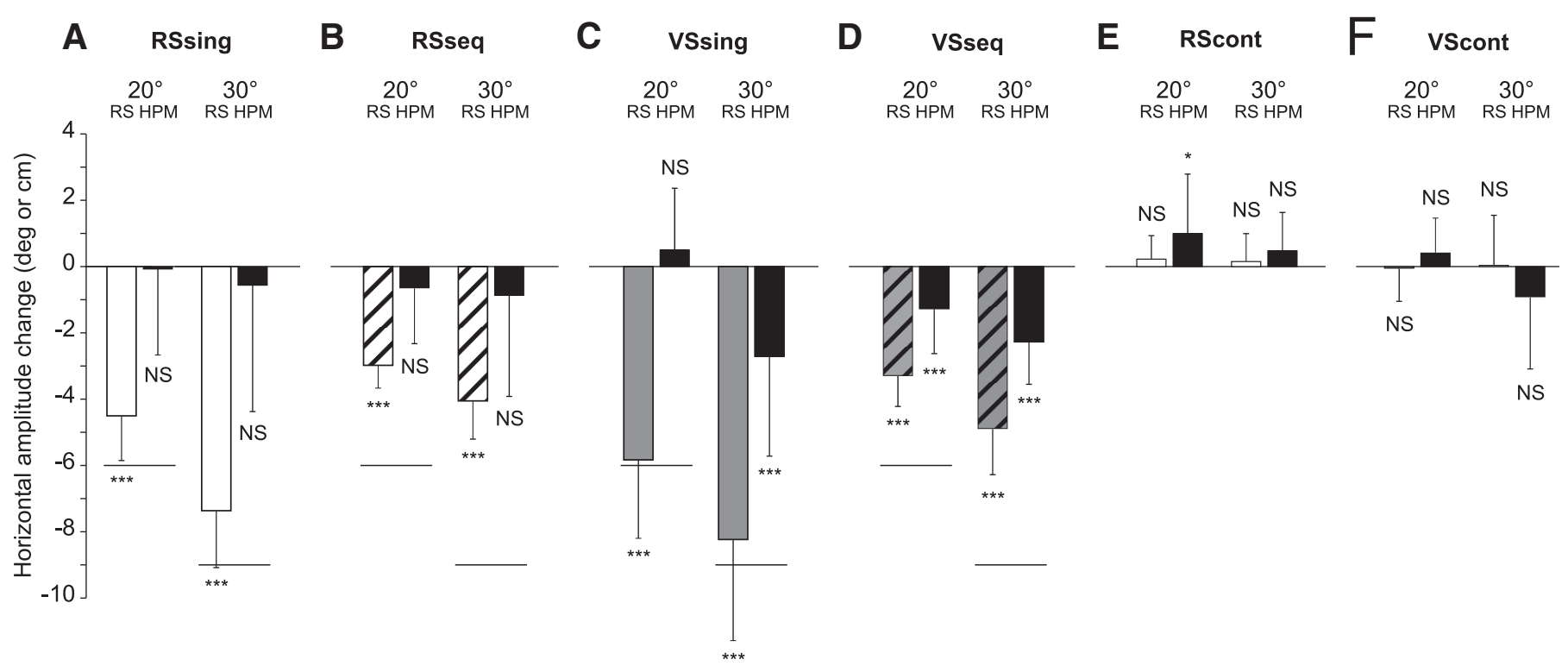

FIG. 4. Horizontal amplitude changes between preexposure and postexposure phases of saccades and HPM for each required vector $\left(20^{\circ} / 30^{\circ}\right)$ in all experimental sessions. Means are computed over the data of 10 subjects in each experimental session except for RSseq $(n=9)$. In all graphs, white, gray, and black bars show RS, VS, and HPM horizontal amplitude change, respectively. Hatched bars show experimental sessions involving saccade sequence task in exposure phases. Error bars show SDs across subjects for each group. Asterisks indicate differences that are statistically significant between preexposure and postexposure phases $(* P<0.05$, $* * * P<0.001$, ANOVA with Newman-Keuls post hoc tests; see RESULTS). Negative values correspond to shortening of horizontal amplitude, congruent with the adaptive amplitude shortening. For $A-D$, bold horizontal lines at -6 and $-9^{\circ}$ show the horizontal amplitude change that would represent a $100 \%$ saccadic adaptation. A: horizontal amplitude change of RS adapted in single saccade task and of HPM in RSsing. B: horizontal amplitude change of RS adapted in saccade sequence task and of HPM in RSseq. $C$ : horizontal amplitude change of VS adapted in single saccade task and of HPM in VSsing. $D$ : horizontal amplitude change of VS adapted in saccade sequence task and of HPM in VSseq. For $E$ and $F$, horizontal amplitude changes of RS (nonadapted), of VS (nonadapted), and of HPM are displayed for RScont and VScont (control sessions).

fatigue) that could have explained the HPM amplitude shortenings observed after VS adaptation.

\section{Amounts of saccadic adaptation}

We computed the amounts of saccadic adaptation for RSsing, RSseq, VSsing, and VSseq, pooling together data for the 20 and $30^{\circ}$ required vectors. The mean amount of saccadic adaptation reached $78.2 \pm 20.5 \%$ in RSsing, $50.4 \pm 6.8 \%$ in RSseq, $94.0 \pm 35.6 \%$ in VSsing, and $54.3 \pm 14.8 \%$ in VSseq. An ANOVA confirmed that these levels of adaptation differed depending on the experimental session $[F(3,35)=9.03, P<$ 0.001]. Post hoc breakdown of this analysis showed no difference between RSsing and VSsing, no difference between RSseq and VSseq ( $P>0.05$, Newman-Keuls post hoc tests), and differences between experimental sessions involving single saccade task and saccade sequence task $(P<0.01$, Newman-Keuls post hoc tests). Thus for similar amounts of adaptation and for similar complexity of the task, comparison between RSsing and VSsing and comparison between RSseq and VSseq allowed us to assess the effect of the type of saccade on the amount of transfer of saccadic adaptation to HPM.

\section{Amounts of transfer of saccadic adaptation to HPM}

Transfer of adaptation was quantified for the conditions in which statistically significant shortenings of HPM amplitude were observed. These amounts reached $32.9 \pm 46.1 \%$ for the $30^{\circ}$ required vector of VSsing and reached $44.3 \pm 48.5$ and $46.6 \pm 21.2 \%$, respectively, for the 20 and $30^{\circ}$ required vectors of VSseq. It is worth noting here that the highest amount of adaptation transfer was observed in VSseq, a condition that induced an amount of adaptation smaller than that observed in VSsing.

\section{Transfer of saccadic adaptation between saccade types}

Finally, transfers of adaptation between the two saccade types were also assessed. Figure $3 A$ presents results of a representative subject in RSsing. VS amplitude was largely reduced after RSsing-Exposure (VS-PRE $=30.1 \pm 1.5^{\circ}$, VS-POST $=27.3 \pm 1.6^{\circ}$ ). Dividing this change of VS amplitude $\left(2.8^{\circ}\right)$ by the adaptive reduction of RS amplitude $\left(7.2^{\circ}\right)$ yields a transfer of RS adaptation to VS of $38.9 \%$ for this subject. Results for one subject of VSseq are presented in Fig. $3 B$. RS amplitude was also affected by VSseq-Exposure, as observed by the $5^{\circ}$ difference between PRE $\left(28.7 \pm 0.7^{\circ}\right)$ and POST $\left(23.7 \pm 1.2^{\circ}\right)$, revealing a $76.9 \%$ transfer of the VS adaptive amplitude change $\left(6.5^{\circ}\right)$ to RS for this subject.

The amounts of transfer of adaptation between saccade types were computed and averaged on the 20 and $30^{\circ}$ required vectors because values for the two amplitudes were not statistically different [ANOVA, $F(3,35)=1.90, P>0.05$ ]. Large transfers were found in all experimental sessions (RSsing to $\mathrm{VS}=56.7 \pm 21.0 \%$, RSseq to VS $=97.0 \pm 17.2 \%$, VSsing to $\mathrm{RS}=82.9 \pm 29.8 \%$, VSseq to $\mathrm{RS}=74.7 \pm 17.1 \%$ ) but differed depending on Experimental Session [ANOVA, $F(3,35)=6.55, P<0.01]$. Post hoc breakdown showed that the only significant differences between these transfers of adaptation were between RSsing to VS (56.7\%) and VSsing to RS (82.9\%) and between RSsing (56.7\%) to VS and RSseq to VS (97.0\%; $P<0.05$, Newman-Keuls post hoc tests). 


\section{I S C U S S I O N}

The present study demonstrates, for the first time to our knowledge, that the generalization of saccadic adaptation to hand pointing movements (HPM) depends on the type of saccades involved. Indeed, adaptation of voluntary saccades (VS) largely affected HPM amplitude, especially when this adaptation involved scanning voluntary saccades performed in a saccade sequence task. In contrast, adaptation of reactive saccade (RS) induced either in a single saccade task or in a saccade sequence task had no effect on HPM amplitude. Control experiments confirmed that the observed changes of HPM amplitude after VS adaptation are not explained by nonspecific factors. Our results also show large reciprocal transfer of adaptation between RS and VS.

\section{Comparison with previous studies}

As stated in the INTRODUCTION, previous studies addressing the transfer of saccadic adaptation to HPM led to conflicting conclusions (Bekkering et al. 1995; Kroller et al. 1999). Our results solve this controversy by demonstrating that this transfer depends largely on the type of saccades adapted (i.e., RS or VS). Indeed, Bekkering and colleagues found a large transfer with an exposure paradigm inducing adaptation of saccades that were likely of the VS type (simultaneously presented targets). The greater amount of transfer reported in Bekkering et al.'s study (74\%), relative to ours (46\% in VSseq), probably reflects the additive effect of the coupling between hand and eye movement that was avoided in our study (see INTRODUCTION). In addition, Kroller et al. (1999) reported a weak but statistically significant transfer of RS adaptation to HPM (17\% on average), whereas we found none. This slight difference could be related to the fact that saccadic adaptation was elicited in the head-unrestrained condition in Kroller et al.'s experiments, rather than in the head-restrained condition in ours. A study in the head-unrestrained monkey has shown that adapting saccadic gaze shifts induces amplitude modifications in both eye and head displacements (Phillips et al. 1997). Therefore although similar evidence is still lacking in humans, the head component of adapted gaze shifts may have contributed to the transfer of adaptation to HPM in Kroller et al.'s study. Concerning the transfer of adaptation between saccade types, we found large amounts of transfer of adaptation between RS and VS. This result is consistent with the trend of recent studies showing transfer of adaptation between these two saccade types (Alahyane et al. 2007; Collins and Doré-Mazars 2006; Fujita et al. 2002). Interestingly, these recent studies and our results tend to reconcile human data with monkey data (Fuchs et al. 1996).

\section{Evidence for a continuum from reactive to voluntary saccades}

Saccades are usually classified in two distinct categories: reactive and voluntary. Our results lead us to consider instead that saccades form a continuum from strongly reactive saccades to strongly voluntary saccades, as recently proposed by Walker and McSorley (2006). Three results of our study are compatible with this hypothesis. First, for RS sessions, the latency measured during the exposure phase tended to be longer for RS produced in sequence $(270 \pm 27 \mathrm{~ms})$ than for RS generated in a single saccade task $(210 \pm 24 \mathrm{~ms})$. Note that the latency of the former is comparable to that reported previously for VS (267 $\pm 16 \mathrm{~ms})$ by Collins and Doré-Mazars (2006). Furthermore, there was a slight trend of HPM amplitude reduction after the adaptation of RS produced in sequence but not after the adaptation of a single RS. Although not statistically significant, these differences of latency and of amount of transfer to HPM suggest a functional distinction between RS saccades produced in a single saccade task and RS produced in a saccade sequence task. Second, for VS sessions, differences of the amount of transfer to HPM similarly suggest that VS produced in a single saccade task can be functionally differentiated from VS produced in a saccade sequence task. Indeed, an advantage was found for the latter in a comparison of both the mean transfer magnitude (32.9\% for VSsing vs. $45.5 \%$ for VSseq) and the number of cases in which a significant transfer occurred for the two required vectors (1/2 for VSsing vs. $2 / 2$ for VSseq). Third, our results of transfer of adaptation between RS and VS also provide meaningful information. On the one hand, the pattern of reciprocal transfers between RSseq and VSsing did not replicate the asymmetry favoring the transfer of VS adaptation to RS (Alahyane et al. 2007; Collins and Doré-Mazars 2006; Fujita et al. 2002). The high and symmetrical transfers of adaptation instead suggest that RS produced in a saccade sequence task are functionally close to VS produced in a single saccade task. On the other hand, testing the pattern of adaptation transfer between the most classical and extreme conditions (RSsing and VSseq) replicate the asymmetrical pattern of results favoring the transfer of adaptation from VS to RS. Altogether, these three lines of observations suggest that saccades tested in our four conditions can be ordered to form the following reactive-to-voluntary continuum: RSsingRSseq-VSsing-VSseq.

We can only speculate why the saccade sequence tasks seem to favor saccade generation in a more voluntary mode. One reason could be that the larger number of stimuli presented at any given time would decrease the relative saliency of the target for the impending saccade. A redistribution of attentional resources would thus be required to appropriately select the next target, which may reinforce the voluntary nature of these saccades. Globally, results of the present study argue for a principle of generalization of saccadic adaptation to hand pointing movements: the more voluntary the saccades, the larger the transfer of their adaptation. The absence of transfer of adaptation in the case of the $20^{\circ}$ required vector in VSsing is the only minor result that does not fit with this scheme. This result remains unclear and requires further experiments to determine the influence of the amplitude in the intermediate condition involving VS adapted in a single saccade task.

\section{Similar error signals, different patterns of generalization}

From a functional point of view, one may ask why do similar error signals in RS and VS exposure phases lead to such differences in patterns of transfer of saccadic adaptation to HPM? One possibility is that for any given type of saccades, some sensorimotor transformation processes are more reliable and are given a stronger weight than others. As a consequence of this greater reliability, they would be less prone to adaptive changes. In the case of the most reactive saccades, given the strong stimulus saliency, the CNS would weight early visual processing as the most reliable, relative to subsequent motor preparation (as indicated by the short saccade latencies). The 
CNS would consequently attribute the postsaccadic error created by the double-step paradigm as a motor planning error. In this case, the adaptive processes would remain confined to the motor system that has encountered this error (i.e., the saccadic system) and no transfer to other motor systems would occur. Instead, for the most voluntary saccades, the selection of the target from the visual scene would imply reorientation of the attention to internally attribute a higher saliency to the target of the impending movement (see review of Colby and Goldberg 1999). This attentional process and the self-paced initiation of the response strongly depend on top-down processes. In this case, the CNS would weight motor planning as the most reliable and ascribe the postsaccadic error induced by the double-step paradigm to an error in target localization or in early sensorimotor transformation processes. Further studies are required to determine whether the stronger transfer of VS adaptation-relative to RS adaptation-also holds for other body effectors and whether VS adaptation can influence target localization in visual perceptual tasks.

\section{Implications for the neurophysiological substrates of $R S$ adaptation}

The control of RS amplitude by the cerebellum involves vermal lobules VI and VII and the caudal part of the fastigial nucleus (cFN) (Fuchs et al. 1993; Goffart and Pelisson 1998; Ohtsuka and Noda 1992, 1995; Pelisson et al. 2003; Robinson et al. 1993). The vast majority of the studies concerning saccadic adaptation have used protocols eliciting saccades that correspond to the definition of RS. It has been shown that the cerebellar network involved in the amplitude control of RS is also involved in their adaptive control (Barash et al. 1999; Desmurget et al. 1998; Goldberg et al. 1993; Inaba et al. 2003; Optican and Robinson 1980; Scudder and Mcgee 2003; Straube et al. 2001; Takagi et al. 1998) and that the cerebellar zones involved in the control of hand movements differ from those controlling RS (Nitschke et al. 2005). In addition, the cerebellar network involved in RS adaptive control is connected with peripheral structures of the saccadic system, i.e., the superior colliculus (SC) and the saccadic burst neurons in the reticular formation (for reviews see Pelisson et al. 2003; Scudder et al. 2002). Thus these brain stem structures may also be involved in the adaptive control of RS, a possibility that is further supported by recording and microstimulation experiments in monkeys (Edelman and Goldberg 2002; Frens and VanOpstal 1997) and behavioral studies in humans (Alahyane et al. 2004, 2007; Hopp and Fuchs 2002, 2006). The SC and reticular burst neurons are classically not involved in the control of HPM [but see Courjon et al. (2004) and Lunenburger et al. (2001) for a role of the SC in arm control]. Taken together, all these results argue for the existence of a network specific for the control of RS adaptation. Our demonstration that HPM are not modified by RS adaptation provides further argument for this scheme. The large amounts of transfer of RS adaptation to VS in RSsing observed in the present study (57\%) are consistent with this scheme. Indeed, the production of both RS and VS involves the SC and the reticular saccadic premotor neurons (Hanes and Wurtz 2001; Scudder et al. 2002). Direct adaptive modifications of these structures or changes of the cerebellar influences on them after RS adaptation should lead to large changes in VS control.

\section{Implications for the neurophysiological substrates of VS adaptation}

Much less is known concerning the neural substrates of VS adaptation. Our demonstration that the update of visuomotor transformation induced by this type of saccade is not effector specific opens several possibilities. Hypothetical involvement in VS adaptation of the cortical level and of the cerebellar level will be successively discussed.

At the cortical level, the influence of a visuomotor adaptation for hand movements has already been demonstrated to modify the activity of a large frontoparietal network (Diedrichsen et al. 2005; Wise et al. 1998). In contrast, to our knowledge there is no evidence of changes of cortical neural activity related to adaptation of saccadic eye movements. A potential locus of these modulations could be the posterior parietal cortex (PPC), which forms a fundamental node in the sensorimotor transformations required to produce movements toward visual targets. A first possible explanation of our results of transfer of adaptation is the following. Among functional subdivisions of the PPC, the lateral intraparietal area (LIP) has been proposed to be dedicated primarily, if not exclusively, for saccadic eye movements (Gnadt and Andersen 1988; Platt and Glimcher 1998) and the parietal reach region (PRR) to be dedicated primarily for hand movements (Galletti et al. 2003; Snyder et al. 1997). It has also been clearly demonstrated that these two areas code location of visual targets in a common and eye-centered reference frame (Andersen and Buneo 2002; Cohen and Andersen 2002). Behavioral studies also reported evidence in favor of this common eye-centered reference frame (e.g., Henriques et al. 1998). If this common reference frame is biased by VS adaptation, then the coding of target position would be modified both in LIP and in PRR, and HPM amplitude would consequently be modified. Similarly, a strong influence of eye position has also been observed in the dorsal premotor cortex (PMd) involved in arm control (Boussaoud et al. 1998). Thus frontal cortical activity modulations arising from VS adaptation could also contribute to the observed transfer to HPM. A second possible explanation should also be considered. Based on results of functional imaging studies, it has been proposed that LIP and the frontal eye fields (FEF) could function in an effector-independent way (Astafiev et al. 2003; Connolly et al. 2000; Levy et al. 2007). Therefore areas LIP and FEF would be located upstream with respect to the hand-specialized areas (PRR and PMd) and to the divergence of processing streams for each effector (Abeele and Bock 2003; Morton and Bastian 2004). Thus these areas are potential anatomical candidates where changes related to VS adaptation would translate into modifications in HPM.

The cerebellum is classically involved in many types of visuomotor adaptation (Houk et al. 1996; Ito 2000; Pisella et al. 2005; Thach 1998; Thach et al. 1992) and can be considered to constitute a key structure concerning transfers of adaptation (Bloedel 2004; Boyden et al. 2004; Lewis 2003; Shimansky et al. 2004; Wainscott et al. 2005). Nevertheless, its implication in VS adaptation is still uncertain. The control of HPM involves the anterior lobe of the cerebellum (Thach et al. 1992), but could additionally concern lateral zones of the posterior lobe (Grodd et al. 2001). Nitschke et al. (2005) confirmed the implication of a posterolateral zone in generation of a hand movement and further provided the interesting observation that the production of VS led to 
activation of a lateral zone in the posterior lobe that overlaps with the posterolateral hand movement zone. Our results of a large transfer of VS adaptation to HPM are compatible with VS adaptation directly involving these lateral cerebellar zones that are common to HPM and saccades. Such a hypothesis is supported by preliminary data in cerebellar patients, suggesting that lateral parts of the cerebellum are necessary for the adaptation of VS (Pelisson et al. 2006).

It is worth noting that these cortical and cerebellar hypotheses concerning VS adaptation are not mutually exclusive. Indeed, the cerebellum (especially its lateral zones) forms several cortico-cerebello-cortical loops with frontal premotor areas and PPC areas (Amino et al. 2001; Middleton and Strick 2000; Ramnani 2006; Yamamoto et al. 2004). Thus adaptive modifications occurring in cerebellar networks probably affect cortical activity. Finally, the large amounts of transfer of VS adaptation to RS could be explained either by an influence of VS adaptation at a stage of coding of the target location or through lateral cerebellar influences on the SC and the reticular saccadic premotor neurons, structures that are shared for the control of RS and VS.

In conclusion, our results demonstrate that the transfer of saccadic adaptation to HPM depends essentially on the nature of saccade triggering-i.e., external or internal-revealing a more general update of visuomotor transform by adaptation of internally triggered VS than by adaptation of externally triggered RS.

\section{A C K N O W LED G MENTS}

The authors acknowledge P.-M. Bernier and F. Sarlegna for comments on the manuscript and F. Buloup for technical assistance and software development (Docometre).

\section{REFERENCES}

Abeele S, Bock O. Transfer of sensorimotor adaptation between different movement categories. Exp Brain Res 148: 128-132, 2003.

Alahyane N, Koene A, Pelisson D. Transfer of adaptation from visually guided saccades to averaging saccades elicited by double visual targets. Eur J Neurosci 20: 827-836, 2004.

Alahyane N, Salemme R, Urquizar C, Cotti J, Guillaume A, Vercher JL, Pelisson D. Oculomotor plasticity: are mechanisms of adaptation for reactive and voluntary saccades separate? Brain Res 1135: 107-121, 2007.

Amino Y, Kyuhou S, Matsuzaki R, Gemba H. Cerebello-thalamo-cortical projections to the posterior parietal cortex in the macaque monkey. Neurosci Lett 309: 29-32, 2001.

Andersen RA, Buneo CA. Intentional maps in posterior parietal cortex. Annu Rev Neurosci 25: 189-220, 2002.

Astafiev SV, Shulman GL, Stanley CM, Snyder AZ, Van Essen DC, Corbetta M. Functional organization of human intraparietal and frontal cortex for attending, looking, and pointing. J Neurosci 23: 4689-4699, 2003.

Barash S, Melikyan A, Sivakov A, Zhang MS, Glickstein M, Thier P. Saccadic dysmetria and adaptation after lesions of the cerebellar cortex. J Neurosci 19: 10931-10939, 1999.

Bekkering H, Abrams RA, Pratt J. Transfer of saccadic adaptation to the manual motor system. Hum Mov Sci 14: 155-164, 1995.

Bloedel JR. Task-dependent role of the cerebellum in motor learning. In: Brain Mechanisms for Integration of Posture and Movement (Progress in Brain Research), edited by Mori S, Stuart DG, Wiesendanger M. Amsterdam: Elsevier, 2004, vol. 143, p. 319-329.

Boussaoud D, Jouffrais C, Bremmer F. Eye position effects on the neuronal activity of dorsal premotor cortex in the macaque monkey. J Neurophysiol 80: 1132-1150, 1998.

Boyden ES, Katoh A, Raymond JL. Cerebellum-dependent learning: the role of multiple plasticity mechanisms. Annu Rev Neurosci 27: 581-609, 2004.
Bridgeman B, Hendry D, Stark L. Failure to detect displacement of the visual world during saccadic eye movements. Vision Res 15: 719-722, 1975.

Cohen YE, Andersen RA. A common reference frame for movement plans in the posterior parietal cortex. Nat Rev Neurosci 3: 553-562, 2002.

Colby CL, Goldberg ME. Space and attention in parietal cortex. Апnи Rev Neurosci 22: 319-349, 1999.

Collins T, Doré-Mazars K. Eye movement signals influence perception: evidence from the adaptation of reactive and volitional saccades. Vision Res 46: 3659-3673, 2006.

Connolly JD, Goodale MA, Desouza JFX, Menon RS, Vilis T. A comparison of frontoparietal fMRI activation during anti-saccades and anti-pointing. J Neurophysiol 84: 1645-1655, 2000.

Cotti J, Guillaume A, Alahyane N, Pelisson D, Vercher J-L. Adaptation of voluntary saccades, but not of reflexive saccades, transfers to hand pointing movements. Soc Neurosci Abstr 736.1, 2006.

Courjon JH, Olivier E, Pelisson D. Direct evidence for the contribution of the superior colliculus in the control of visually guided reaching movements in the cat. $J$ Physiol 556: 675-681, 2004.

Desmurget M, Pelisson D, Urquizar C, Prablanc C, Alexander GE, Grafton ST. Functional anatomy of saccadic adaptation in humans. Nat Neurosci 1: 524-528, 1998.

Deubel H. Separate adaptive mechanisms for the control of reactive and volitional saccadic eye-movements. Vision Res 35: 3529-3540, 1995.

Diedrichsen J, Hashambhoy Y, Rane T, Shadmehr R. Neural correlates of reach errors. J Neurosci 25: 9919-9931, 2005.

Edelman JA, Goldberg ME. Effect of short-term saccadic adaptation on saccades evoked by electrical stimulation in the primate superior colliculus. J Neurophysiol 87: 1915-1923, 2002.

Erkelens CJ, Hulleman J. Selective adaptation of internally triggered saccades made to visual targets. Exp Brain Res 93: 157-164, 1993.

Feys P, Helsen WF, Liu XG, Nuttin B, Lavrysen A, Swinnen SP, Ketelaer P. Interaction between eye and hand movements in multiple sclerosis patients with intention tremor. Mov Disord 20: 705-713, 2005.

Frens MA, VanOpstal AJ. Monkey superior colliculus activity during shortterm saccadic adaptation. Brain Res Bull 43: 473-483, 1997.

Fuchs AF, Reiner D, Pong M. Transfer of gain changes from targeting to other types of saccades in the monkey: constraints on possible sites of saccadic gain adaptation. J Neurophysiol 76: 2522-2535, 1996.

Fuchs AF, Robinson FR, Straube A. Role of the caudal fastigial nucleus in saccade generation. I. Neuronal discharge patterns. J Neurophysiol 70: 1723-1740, 1993.

Fujita M, Amagai A, Minakawa F, Aoki M. Selective and delay adaptation of human saccades. Cogn Brain Res 13: 41-52, 2002.

Galletti C, Kutz DF, Gamberini M, Breveglieri R, Fattori P. Role of the medial parieto-occipital cortex in the control of reaching and grasping movements. Exp Brain Res 153: 158-170, 2003.

Gaveau V, Alahyane N, Salemme R, Desmurget M. Self-generated saccades do not modify the gain of adapted reactive saccades. Exp Brain Res 162: 526-531, 2005.

Gaymard B, Lynch J, Ploner CJ, Condy C, Rivaud-Pechoux S. The parieto-collicular pathway: anatomical location and contribution to saccade generation. Eur J Neurosci 17: 1518-1526, 2003.

Gnadt JW, Andersen RA. Memory related motor planning activity in posterior parietal cortex of macaque. Exp Brain Res 70: 216-220, 1988.

Goffart L, Pelisson D. Orienting gaze shifts during muscimol inactivation of caudal fastigial nucleus in the cat. I. Gaze dysmetria. J Neurophysiol 79: 1942-1958, 1998.

Goldberg ME, Musil SY, Fitzgibbon EJ, Smith M, Olson CR. The role of the cerebellum in the control of saccadic eye movements. In: Role of the Cerebellum and Basal Ganglia in Voluntary Movements, edited by Mano N, Hamada I, DeLong MR. Amsterdam: Elsevier, 1993, p. 203-210.

Grodd W, Hulsmann E, Lotze M, Wildgruber D, Erb M. Sensorimotor mapping of the human cerebellum: fMRI evidence of somatotopic organization. Hum Brain Mapp 13: 55-73, 2001.

Hanes DP, Wurtz RH. Interaction of the frontal eye field and superior colliculus for saccade generation. J Neurophysiol 85: 804-815, 2001.

Henriques DYP, Klier EM, Smith MA, Lowy D, Crawford JD. Gazecentered remapping of remembered visual space in an open-loop pointing task. J Neurosci 18: 1583-1594, 1998.

Hopp JJ, Fuchs AF. Investigating the site of human saccadic adaptation with express and targeting saccades. Exp Brain Res 144: 538-548, 2002.

Hopp JJ, Fuchs AF. The characteristics and neuronal substrate of saccadic eye movement plasticity. Prog Neurobiol 72: 27-53, 2004. 
Hopp JJ, Fuchs AF. Amplitude adaptation occurs where a saccade is represented as a vector and not as its components. Vision Res 46: 3121-3128, 2006.

Houk JC, Buckingham JT, Barto AG. Models of the cerebellum and motor learning. Behav Brain Sci 19: 368-383, 1996.

Imamizu H, Shimojo S. The locus of visual-motor learning at the task of manipulator level-implications from intermanual transfer. $J$ Exp Psychol Hum Percept Perform 21: 719-733, 1995.

Inaba $\mathbf{N}$, Iwamoto $\mathbf{Y}$, Yoshida $\mathbf{K}$. Changes in cerebellar fastigial burst activity related to saccadic gain adaptation in the monkey. Neurosci Res 46: 359-368, 2003.

Ito M. Mechanisms of motor learning in the cerebellum. Brain Res 886: 237-245, 2000

Kroller J, De Graaf JB, Prablanc C, Pelisson D. Effects of short-term adaptation of saccadic gaze amplitude on hand-pointing movements. Exp Brain Res 124: 351-362, 1999.

Levy I, Schluppeck D, Heeger DJ, Glimcher PW. Specificity of human cortical areas for reaches and saccades. J Neurosci 27: 4687-4696, 2007.

Lewis RF. Context-dependent adaptation of visually-guided arm movements and vestibular eye movements: role of the cerebellum. Cerebellum 2: 123-130, 2003.

Lunenburger L, Kleiser R, Stuphorn V, Miller LE, Hoffmann KP. A possible role of the superior colliculus in eye-hand coordination. Prog Brain Res 134: 109-125, 2001.

Matin E. Saccadic suppression: a review and an analysis. Psychol Bull 81: 899-917, 1974.

Middleton FA, Strick PL. Basal ganglia and cerebellar loops: motor and cognitive circuits. Brain Res Rev 31: 236-250, 2000.

Morton SM, Bastian AJ. Prism adaptation during walking generalizes to reaching and requires the cerebellum. J Neurophysiol 92: 2497-2509, 2004.

Nitschke MF, Arp T, Stavrou G, Erdmann C, Heide W. The cerebellum in the cerebro-cerebellar network for the control of eye and hand movements-an fMRI study. Prog Brain Res 148: 151-164, 2005.

Ohtsuka K, Noda H. Burst discharges of fastigial neurons in macaque monkeys are driven by vision-guided and memory-guided saccades but not by spontaneous saccades. Neurosci Res 15: 224-228, 1992.

Ohtsuka K, Noda H. Discharge properties of Purkinje cells in the oculomotor vermis during visually guided saccades in the macaque monkey. $J$ Neurophysiol 74: 1828-1840, 1995.

Optican LM, Robinson DA. Cerebellar-dependent adaptive-control of primate saccadic system. J Neurophysiol 44: 1058-1076, 1980.

Pelisson D, Alahyane N, Fonteille V, Urquizar C, Salemme R, Tilikete C. Oculomotor plasticity: behavioural properties and neural substrates of adaptation of voluntary and of reactive saccades in humans. Soc Neurosci Abstr 736.8, 2006.

Pelisson D, Goffart L, Guillaume A, Quinet J. Visuo-motor deficits induced by fastigial nucleus inactivation. Cerebellum 2: 71-76, 2003.

Phillips JO, Fuchs AF, Ling L, Iwamoto Y, Votaw S. Gain adaptation of eye and head movement components of simian gaze shifts. J Neurophysiol 78: 2817-2821, 1997.
Pisella L, Rossetti Y, Michel C, Rode G, Boisson D, Pelisson D, Tilikete C. Ipsidirectional impairment of prism adaptation after unilateral lesion of anterior cerebellum. Neurology 65: 150-152, 2005.

Platt ML, Glimcher PW. Response fields of intraparietal neurons quantified with multiple saccadic targets. Exp Brain Res 121: 65-75, 1998.

Ramnani N. The primate cortico-cerebellar system: anatomy and function. Nat Rev Neurosc 7: 511-522, 2006.

Robinson FR, Straube A, Fuchs AF. Role of the caudal fastigial nucleus in saccade generation. II. Effects of muscimol inactivation. J Neurophysiol 70: 1741-1758, 1993.

Scudder CA, Kaneko CRS, Fuchs AF. The brainstem burst generator for saccadic eye movements_a modern synthesis. Exp Brain Res 142: 439 462, 2002.

Scudder CA, Mcgee DM. Adaptive modification of saccade size produces correlated changes in the discharges of fastigial nucleus neurons. J Neurophysiol 90: 1011-1026, 2003.

Seidler RD, Bloomberg JJ, Stelmach GE. Patterns of transfer of adaptation among body segments. Behav Brain Res 122: 145-157, 2001.

Shimansky Y, Wang JJ, Bauer RA, Bracha V, Bloedel JR. On-line compensation for perturbations of a reaching movement is cerebellar dependent: support for the task dependency hypothesis. Exp Brain Res 155: 156-172, 2004.

Snyder LH, Batista AP, Andersen RA. Coding of intention in the posterior parietal cortex. Nature 386: 167-170, 1997.

Straube A, Deubel H, Ditterich J, Eggert T. Cerebellar lesions impair rapid saccade amplitude adaptation. Neurology 57: 2105-2108, 2001.

Takagi M, Zee DS, Tamargo RJ. Effects of lesions of the oculomotor vermis on eye movements in primate: saccades. J Neurophysiol 80: 1911-1931, 1998.

Thach WT. What is the role of the cerebellum in motor learning and cognition? Trends Cogn Sci 2: 331-337, 1998.

Thach WT, Goodkin HP, Keating JG. The cerebellum and the adaptive coordination of movement. Anпи Rev Neurosci 15: 403-442, 1992.

Van Donkelaar P, Gauthier GM, Vercher JL, Blouin J. Changes in saccadic and manual motor control after ocular smooth pursuit adaptive modifications. J Mot Behav 28: 315-323, 1996.

Van Donkelaar P, Lee JH, Drew AS. Eye-hand interactions differ in the human premotor and parietal cortices. Hum Mov Sci 21: 377-386, 2002.

Wainscott SK, Donchin O, Shadmehr R. Internal models and contextual cues: encoding serial order and direction of movement. J Neurophysiol 93: 786-800, 2005.

Walker R, McSorley E. The parallel programming of voluntary and reflexive saccades. Vision Res 46: 2082-2093, 2006.

Wise SP, Moody SL, Blomstrom KJ, Mitz AR. Changes in motor cortical activity during visuomotor adaptation. Exp Brain Res 121: 285-299, 1998.

Yamamoto T, Nishimura Y, Matsuura T, Shibuya H, Lin M, Asahara T. Cerebellar activation of cortical motor regions: comparisons across mammals. Prog Brain Res 143: 309-317, 2004. 